\title{
EXPERIMENTAL INVESTIGATIONS ON A COMPACT HEAT EXCHANGER AND OPTIMIZATION USING TAGUCHI TECHNIQUE
}

\author{
Varun Kumar N P ${ }^{1}$, Sunil S ${ }^{2}$, C. Prabhakar Reddy ${ }^{3}$ \\ ${ }^{I}$ Assistant Professor of Mechanical Engineering, AleMS Bidadi \\ varunkumar3603@gmail.com \\ ${ }^{2}$ Assistant Professor of Mechanical Engineering, \\ sunil_mech2003@yahoo.com \\ ${ }^{3}$ Principal and Professor of Mechanical Engineering, SVCE Bengaluru,
}

\begin{abstract}
This present research majorly is done to evaluate the performance of a compact heat exchanger (automobile radiator). The experiment was conducted and the performance was investigated for different inputs of mass flow rate of fluid and temperatures. Various parameters like effectiveness, heat transfer rate etc. Calculated, finding best effectiveness for different mass flow rate of hot fluid at different temperatures, with coolant keeping the dimensions constant to enhance the heat transfer capacity of heat exchangers. A c-program for the formulation and numerical calculation was written and compared with the experimental results. Taguchi technique is used to derive linear equations and linear relations for different parameters. The results from taguchi technique are validated experimentally.
\end{abstract}

Keywords: Radiator, Compact Heat Exchanger, Effectiveness, NTU, Taguchi Technique, C-Program.

\section{INTRODUCTION}

A heat exchanger is a device used to transfer heat between two or more fluids. It consists of an arrangement which allows two fluids usually liquids flow in two different passages, may be flat tubes / circular tubes or any other pattern. Heat exchangers involve heat transfer between the two fluids either in form of conduction, convection or radiation. Some heat-exchangers accommodate direct contact between fluids, and some accommodate an indirect contact transferring heat through solid surface separating the two fluids. Most of heat exchangers would not ideally mix two fluids and they are separated by a heat transfer surface, such types of heat exchangers are called indirect transfer type heat exchangers. The heat transfer rate in an heat exchanger can be increased by increasing fluid flow velocity, mass flow rate and this can be shown in most flow passages that could be used in the heat transfer surfaces of an exchange.

By increasing the number of flow passages in the heat exchanger the designer can reduce flow velocities in a particular application friction power expenditure tends to be high. The loss of heat transfer rate is made up by increasing the surface area which in turn increases the friction power expenditure, according to the above relation reduced heat transfer rate per unit surface area will be considerably less than the friction power reduction.

For a typical gas flow heat exchanger large amount of surface area becomes a main characteristics since the friction power limitations force the designer to arrange for a moderately low mass velocities with low thermal conductivity together with low mass velocities.

\begin{abstract}
A Shell-and-tube Heat Exchanger
Shell and tube heat exchanger is one of the types of heat exchangers which are the most commonly in oil refineries. This type of heat exchanger is best for high-pressure and high-temperature applications. This type of heat exchanger basically consists of a shell with a bundle of tubes enclosed. In the two fluids, one flows through the shell and the other through the tubes. From the surface of the tube heat is transferd from the outer flowing fluid to the inside fluid or vice versa depending on the temperature gradient between the two fluids. If a number of tubes is enclosed in the shell that set is called bundle of tubes. The figure below shows a typical shell and tube heat exchangers
\end{abstract}

\section{B. Compact type heat exchangers:}

Compact heat exchangers are used widely in automobile, chemical industries, aerospace and cryogenics.

The term compactness is a arbitrary reference so as given to the compact heat exchanger, regardless of its structural design the ratio of the heat transfer surface area on single side of the heat exchanger to the volume can be said as the compactness of a heat exchanger. The surface area density on any side greater than $700 \mathrm{~m}^{2} / \mathrm{m}^{3}$ of heat exchanger can be referred as compactness (automobile radiator with area density of nearly $1000 \mathrm{~m}^{2} / \mathrm{m}^{3}$ ). For a shell and tube heat exchanger the area densities are considered from 70 to $\left.500 \mathrm{~m}^{2} / \mathrm{m}^{3}\right)$.

In fact high value of compactness reduces with the volume for the specified heat exchanger performance by considering compact heat exchanger. 


\section{METHODOLGY}

The present research is an evacuation of the heat transfer augmentation in a compact heat exchanger for cooling applications where, already designed and manufactured car radiator is used, which can accommodate flat tube and has folded fins. The experiments are conducted for heat exchange through radiator with different mass flow rate of hot fluid. The radiator inlet is connected to a pipe where hot fluids enter the radiator with the help of $0.37 \mathrm{KW}$ capacity pump. A $2 \mathrm{KW}$ heating coil is attached with tank which heats the fluid inside the tank, that will be acting as the source of heat for the heat exchanger. A high speed automotive fan is incorporated behind the radiator so as to obtain cold fluid which must be directed towards the radiator, through a passage of sheet metal duct. A truncated conical duct is fixed in front of the radiator to avoid any leakage in the flow of the cold fluid. The fan is run by an external power source battery $(12 \mathrm{~V}, 60 \mathrm{~A})$. The outlet of the radiator is connected to the tank through pipes. The inlet and outlet temperatures of the flowing fluid are determined by thermocouples placed inside the hot and cold pipes. The flow rate of the hot fluid is controlled by a control valve which is placed in between pump and the inlet of the radiator. A rotameter is fixed between the radiator and the pump to measure the flow of fluid.

Materials used for experiment

A. TATA Indica Car Radiator:-

\begin{tabular}{|l|l|}
\hline Material & aluminum \\
\hline Tube Inside Thickness & $1 \mathrm{~mm}$ \\
\hline Tube Outer thickness & $2 \mathrm{~mm}$ \\
\hline Length & $600 \mathrm{~mm}$ \\
\hline Number of tubes & 36 \\
\hline Tube width & $360 \mathrm{~mm}$ \\
\hline
\end{tabular}

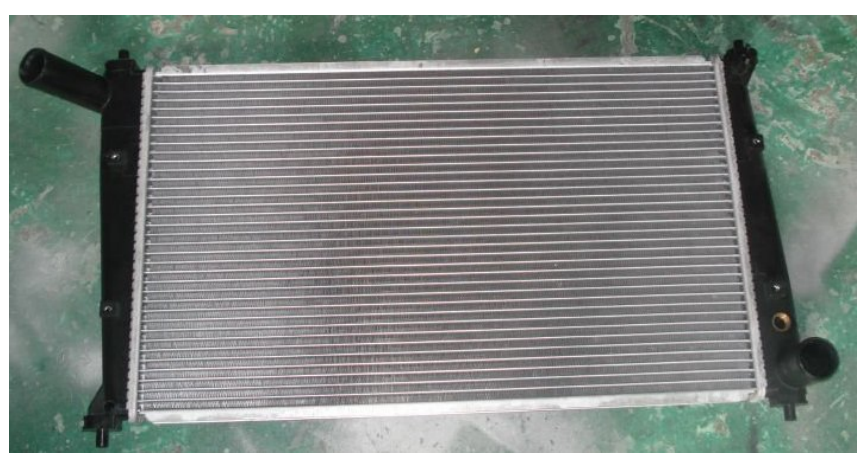

Fig 1:- TATA Indica Car Radiator

\section{A. Anemomerter:-}

Anemometer is used to measure air flow rate range of air up to 3.6 to $90 \mathrm{~km} / \mathrm{h}$ with Accuracy of $3 \%(0.8 \mathrm{~km} / \mathrm{h})$. Also we can measure the inlet and outlet temperature of air.

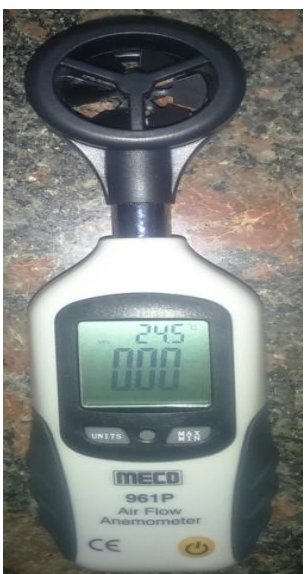

Fig 2. Anemometer

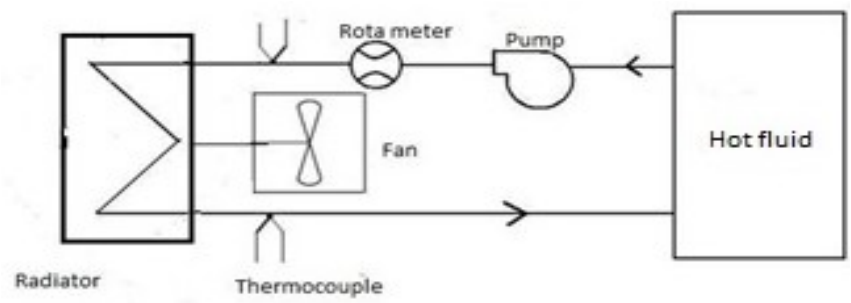

Fig 3 Line diagram of experimental setup

\section{RESULTS AND DISCUSSION}

Sample readings

Table-1 Experimental readings at various coolants

\begin{tabular}{|c|c|c|c|c|c|c|c|c|}
\hline \multirow{2}{*}{$\begin{array}{c}\text { Mass flow } \\
\text { rate of hot } \\
\text { fluid(LPM) } \\
\text { at } 44^{\circ} \mathrm{C}\end{array}$} & \multicolumn{2}{|c|}{$\begin{array}{c}100 \% \text { of } \\
\text { water }\end{array}$} & \multicolumn{2}{|c|}{$\begin{array}{c}60 \% \text { of } \\
\text { water+40 } \\
\text { of coolant }\end{array}$} & \multicolumn{2}{|c|}{$\begin{array}{c}50 \% \text { of } \\
\text { water+50 } \\
\text { of coolant }\end{array}$} & \multicolumn{2}{|c|}{$\begin{array}{c}4 \% \text { of } \\
\text { water+60 } \\
\text { of coolant }\end{array}$} \\
\cline { 2 - 10 } & $\mathrm{T}_{\mathrm{o}}$ & $\varepsilon$ & $\mathrm{T}_{\mathrm{o}}$ & $\varepsilon$ & $\mathrm{T}_{\mathrm{o}}$ & $\varepsilon$ & $\mathrm{T}_{\mathrm{o}}$ & $\varepsilon$ \\
\hline 1.6 & 30 & 0.72 & 32 & 0.72 & 33 & 0.64 & 35 & 0.54 \\
\hline 2.6 & 33 & 0.74 & 34 & 0.65 & 37 & 0.55 & 37 & 0.54 \\
\hline 3.6 & 38 & 0.64 & 37 & 0.60 & 38 & 0.52 & 39 & 0.39 \\
\hline 4.6 & 39 & 0.64 & 39 & 0.57 & 39 & 0.50 & 39 & 0.46 \\
\hline 5.6 & 40 & 0.60 & 40 & 0.62 & 40 & 0.49 & 40 & 0.46 \\
\hline
\end{tabular}

Table-2 Taguchi Technique readings at various coolants

\begin{tabular}{|c|c|c|c|c|c|c|c|c|}
\hline \multirow{2}{*}{$\begin{array}{l}\text { Mass } \\
\text { flow } \\
\text { rate of } \\
\text { hot } \\
\text { fluid } \\
\text { (LPM) } \\
\text { at } \\
44^{\circ} \mathrm{C}\end{array}$} & \multicolumn{2}{|c|}{$\begin{array}{l}100 \% \\
\text { of water }\end{array}$} & \multicolumn{2}{|c|}{$\begin{array}{l}60 \% \text { of } \\
\text { water }+40 \\
\text { of coolant }\end{array}$} & \multicolumn{2}{|c|}{$\begin{array}{l}50 \% \text { of } \\
\text { water }+50 \text { of } \\
\text { coolant }\end{array}$} & \multicolumn{2}{|c|}{$\begin{array}{l}40 \% \text { of } \\
\text { water }+60 \text { of } \\
\text { coolant }\end{array}$} \\
\hline & $\mathrm{T}_{\mathrm{o}}$ & $\varepsilon$ & $\mathrm{T}_{\mathrm{o}}$ & $\varepsilon$ & $\mathrm{T}_{\mathrm{o}}$ & $\varepsilon$ & $\mathrm{T}_{\mathrm{o}}$ & $\varepsilon$ \\
\hline 1.6 & 29.74 & 0.74 & 32 & 0.69 & 33.27 & 0.61 & 35.37 & 0.52 \\
\hline 2.6 & 34.39 & 0.69 & 34 & 0.63 & 35.98 & 0.56 & 36.92 & 0.48 \\
\hline 3.6 & 37.6 & 0.65 & 36 & 0.60 & 38.02 & 0.52 & 38.24 & 0.45 \\
\hline 4.6 & 39.39 & 0.62 & 38 & 0.59 & 39.39 & 0.49 & 39.34 & 0.44 \\
\hline 5.6 & 39.75 & 0.59 & 40 & 0.62 & 40.08 & 0.48 & 40.21 & 0.43 \\
\hline
\end{tabular}




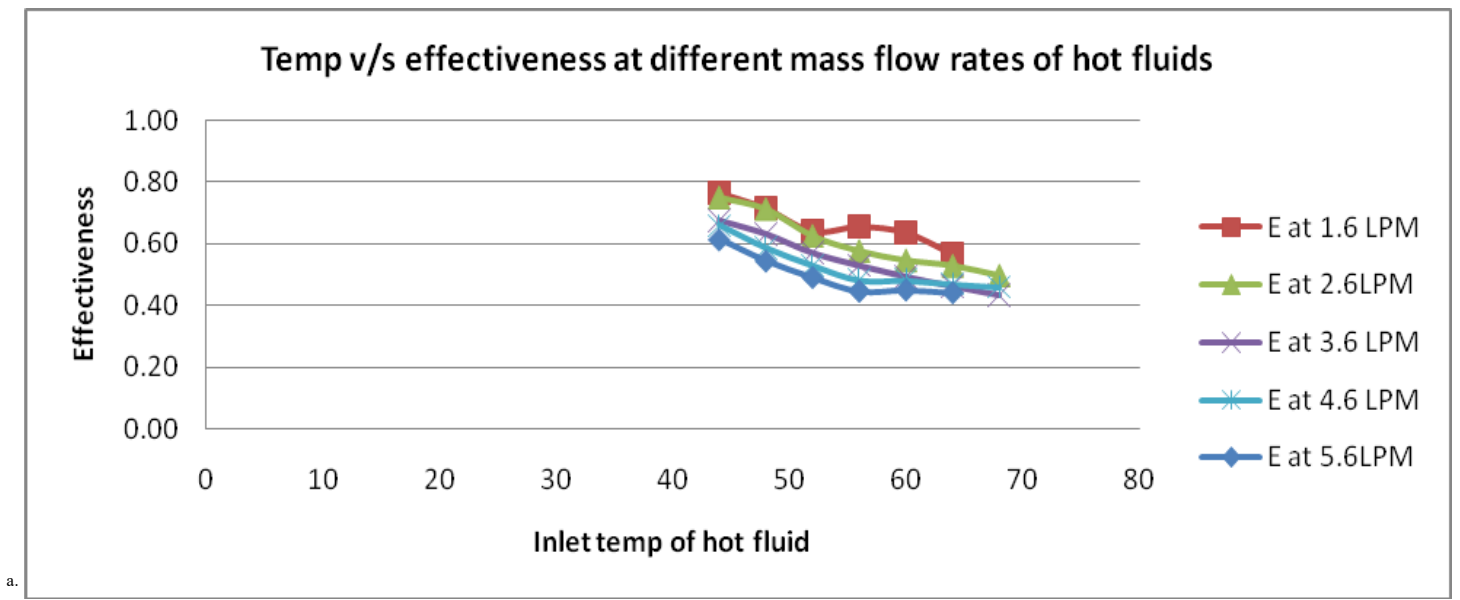

Fig. 1. Effectiveness v/s inlet temp of hot fluid at different mass flow rates for for hot fluid (water)

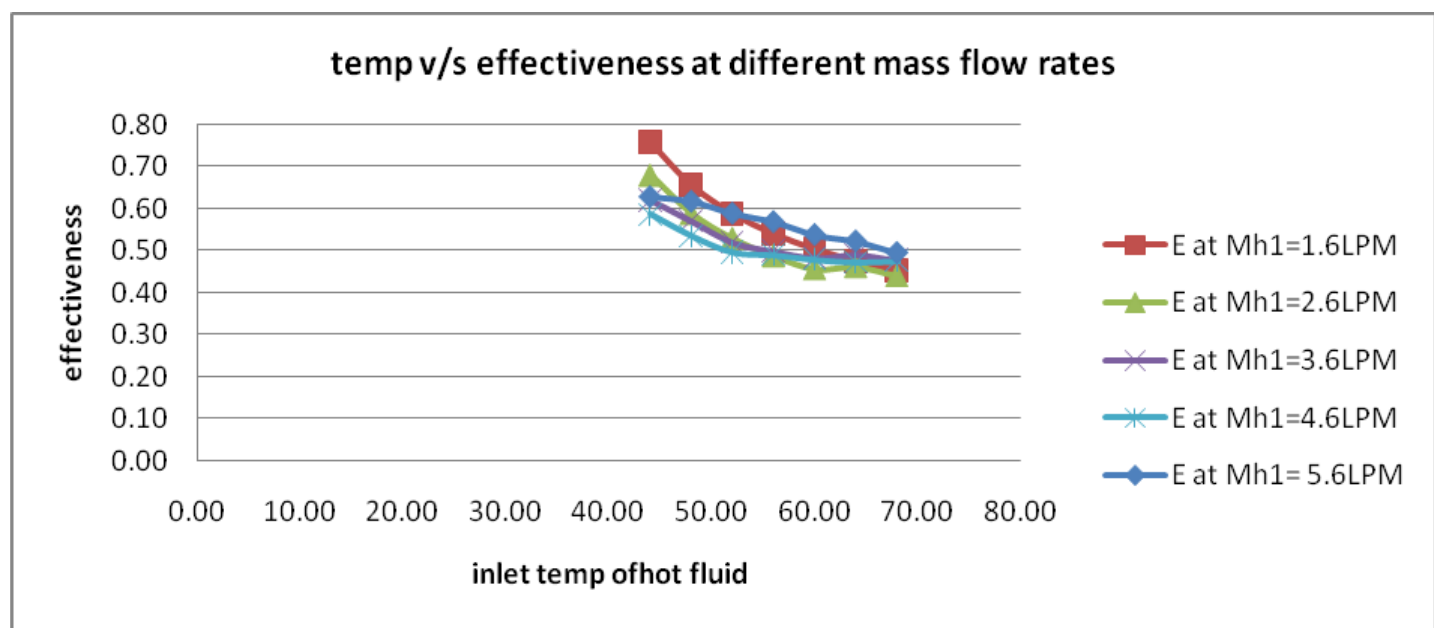

Fig. 2. Effectiveness v/s inlet temp of hot fluid at different mass flow rates for hot fluid (60\% of water)

Fig.1 and Fig. 2 It is observed that maximum effectiveness is obtained at low temperatures and low mass flow rates of hot fluid, also it is observed that with the increase in mass flow rate of hot fluid effectiveness decreases. The maximum effectiveness is obtained at $44{ }^{0} \mathrm{C}$ and 1.6 LPM. Effectiveness is the ratio of actual heat transferred to the maximum possible heat transfer achieved. Maximum possible heat transfer is given by $\mathrm{Cmin} \times($ Thi-Tci). According to the equation the effectiveness of the heat exchanger increases when inlet temperature of hot fluid is decreased or inlet temperature of cold fluid is increased. The contact time between hot and cold fluid is deceses so effectiveness is decreses.

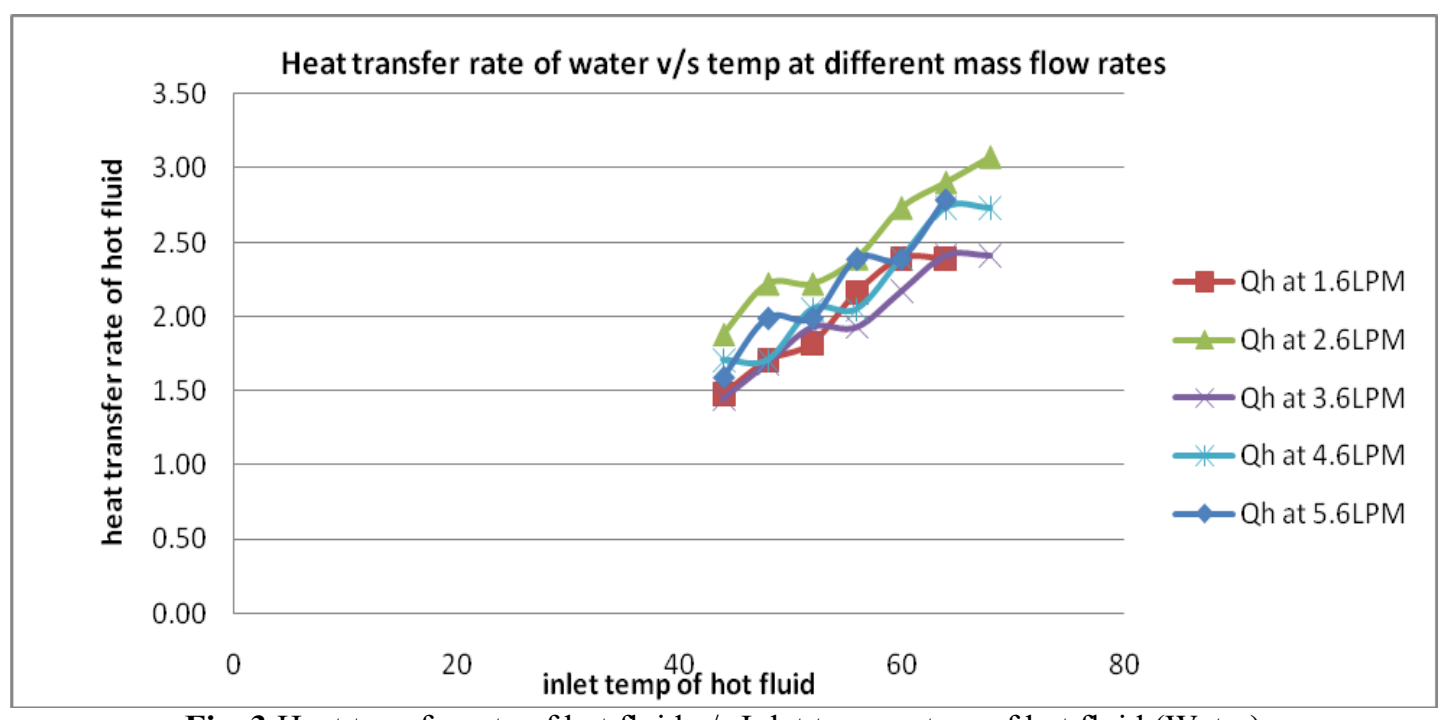

Fig. 3.Heat transfer rate of hot fluid v/s Inlet tempareture of hot fluid (Water) 


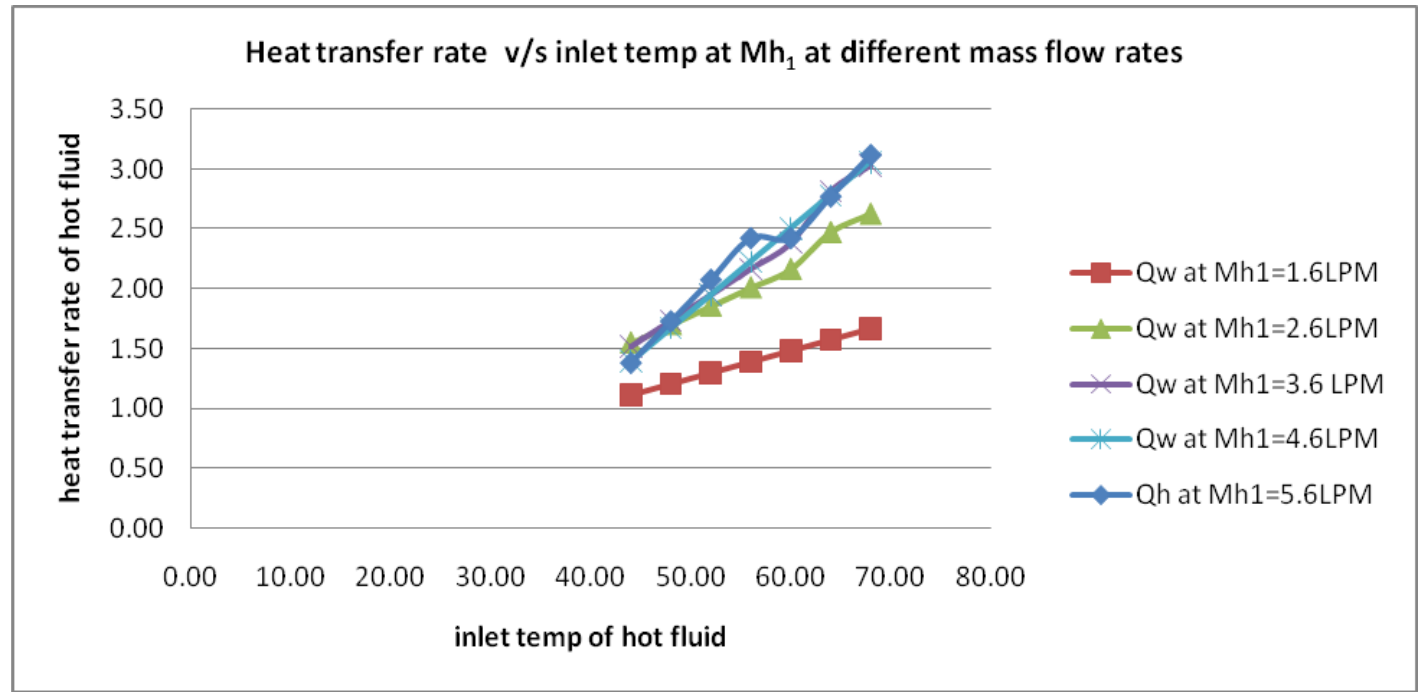

Fig. 4. Heat transfer rate of hot fluid v/s Inlet tempareture of hot fluid (60\% of Water)

Fig.3 Fig.4 It is observed that heat transfer rate of hot fluid increases with increase in inlet temperature of hot fluid. The maximum heat transfer rate is obtained at $68^{\circ} \mathrm{C}$ and 5.6LPM. Effectiveness is the ratio of actual heat transferred to the maximum possible heat transfer achieved. Heat transfer rate of hot fluid is given by $\mathbf{Q}_{\mathbf{h}}=\mathbf{M}_{\mathbf{h}} \times \mathbf{C}_{\mathbf{p h}} \times\left(\mathbf{T}_{\mathbf{h i}}-\mathbf{T}_{\mathbf{h o}}\right)$. According to the equation the effectiveness of the heat exchanger increases when temperature drop of hot fluid is increased. Heat transfer rate is depends on mass flow rate and tempareture difference hence tempareture difference is increses hence heat transfer rate is increses.

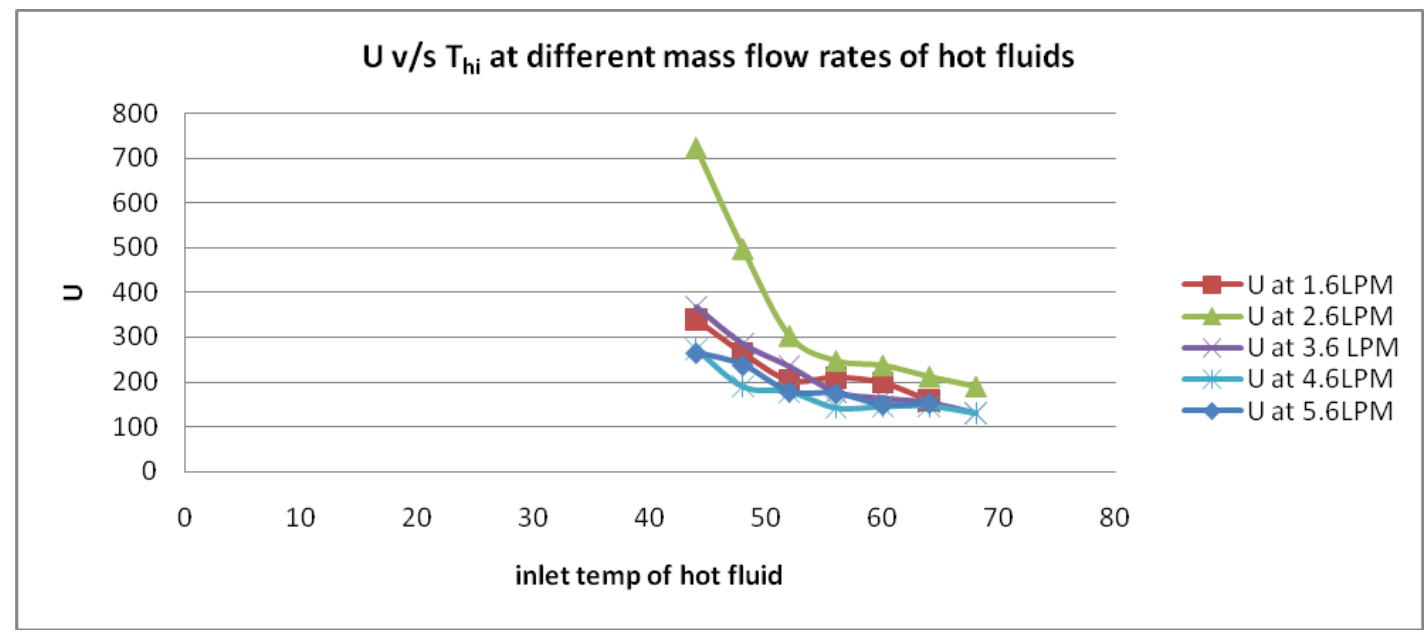

Fig. 5. Overall heat transfer co-efficient v/s inlet temp of hot fluid (water)

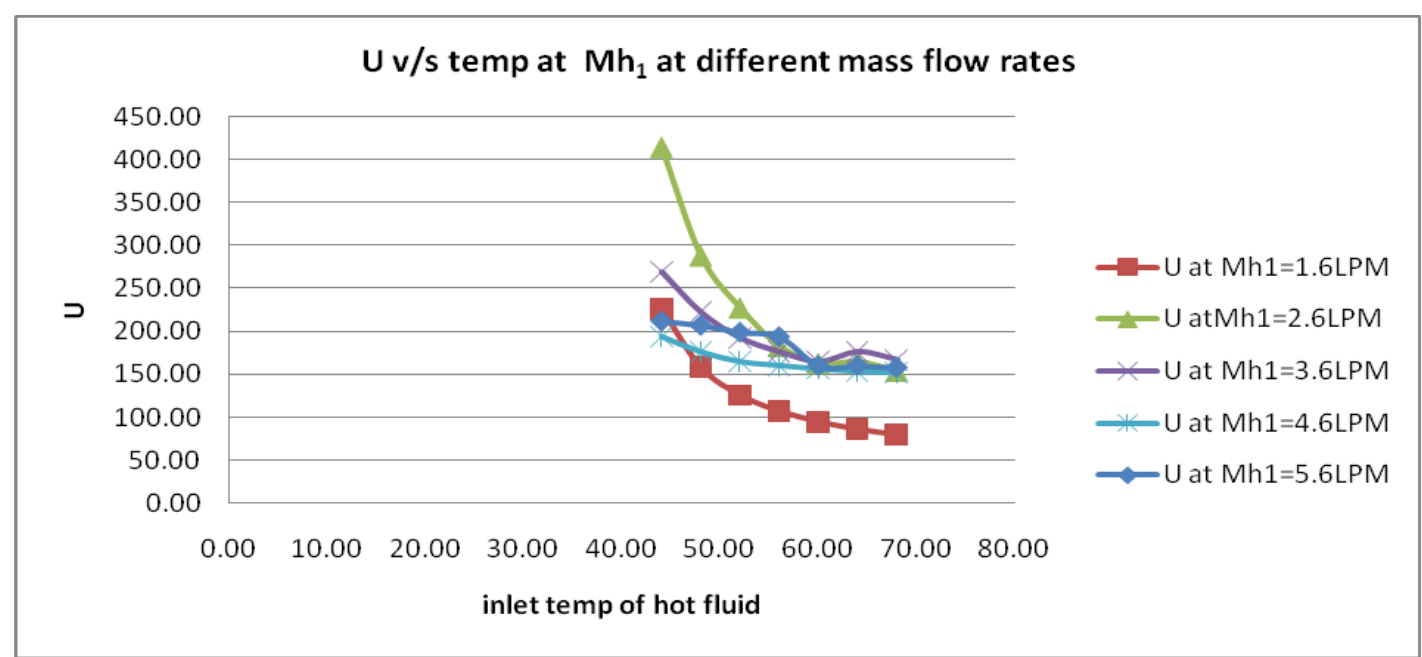

Fig. 6. Overall heat transfer co-efficient v/s inlet temp of hot fluid ( $60 \%$ of water) 
Fig.5 Fig.6 it is observed that overall heat transfer coefficient is higher at lower mass flow rate and lower temperature of hot fluid. As the inlet temperature of hot fluid is increased overall heat transfer co-efficient decreases. Heat transfer rate of hot fluid is given by $\mathbf{Q}=\mathbf{F U A}(\Delta \mathbf{T}) \mathbf{l m}$
According to the equation the overall heat transfer co efficient of the hot fluid increases when log mean temperature decreases and heat transfer rate of hot fluid is increased.

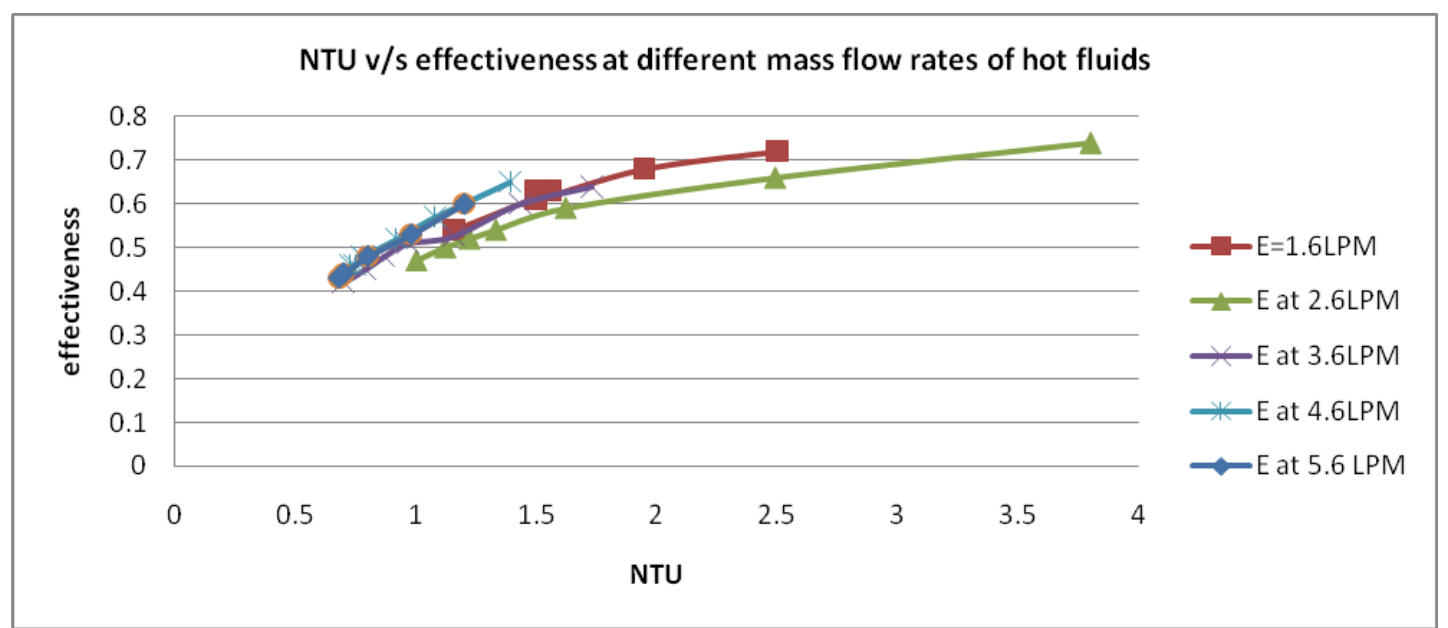

Fig. 7.effectiveness v/s NTU at different mass flow rates for hot fluid (water)

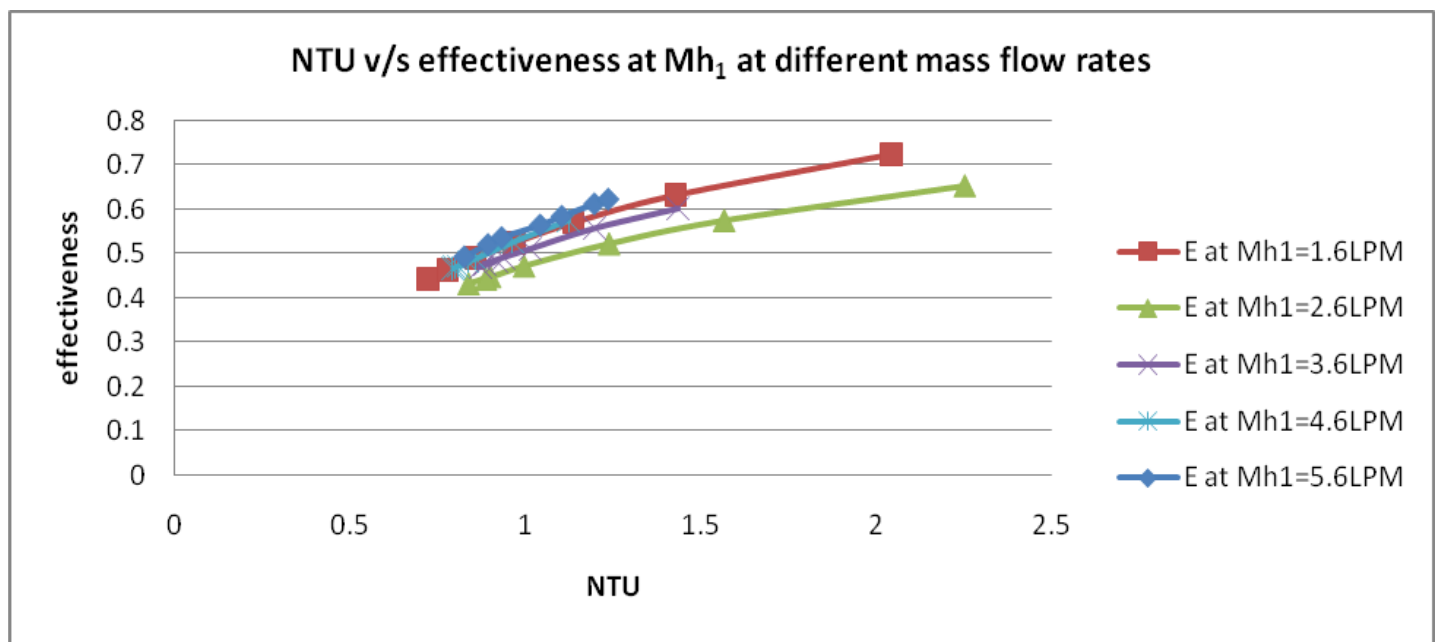

Fig. 8.effectiveness v/s NTU at different mass flow rates for hot fluid (water)

From fig 7, 8 we observed that maximum effectiveness is obtained at higher NTU and low mass flow rate of hot fluid. Also it is observed that mass flow rate of hot fluid increases as NTU decreases. Effectiveness is the ratio of actual heat transferred to the maximum possible heat transfer achieved. Maximum number of transfer units is given by $\mathbf{N}=\mathbf{U A} / \mathbf{C}_{\text {min }}$. According to the equation the effectiveness of the heat exchanger increases when NTU of hot fluid is increased or overall heat transfer co-efficient of hot fluid is increased.

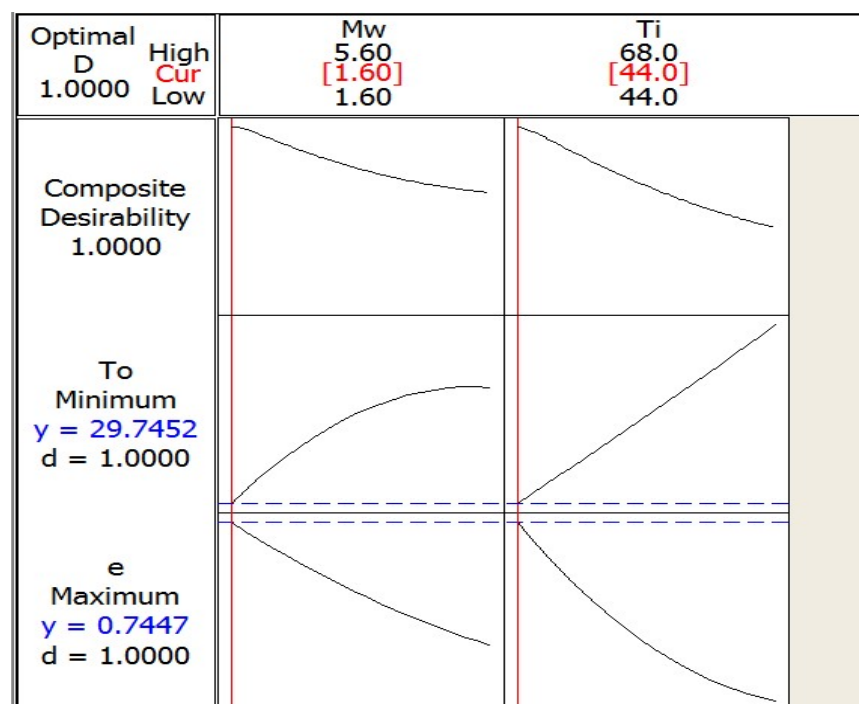

Fig. 9. Optimum graph for Mass flow rate of hot fluid (water) v/s Inlet temperature (Ti) Taguchi Techniqe 


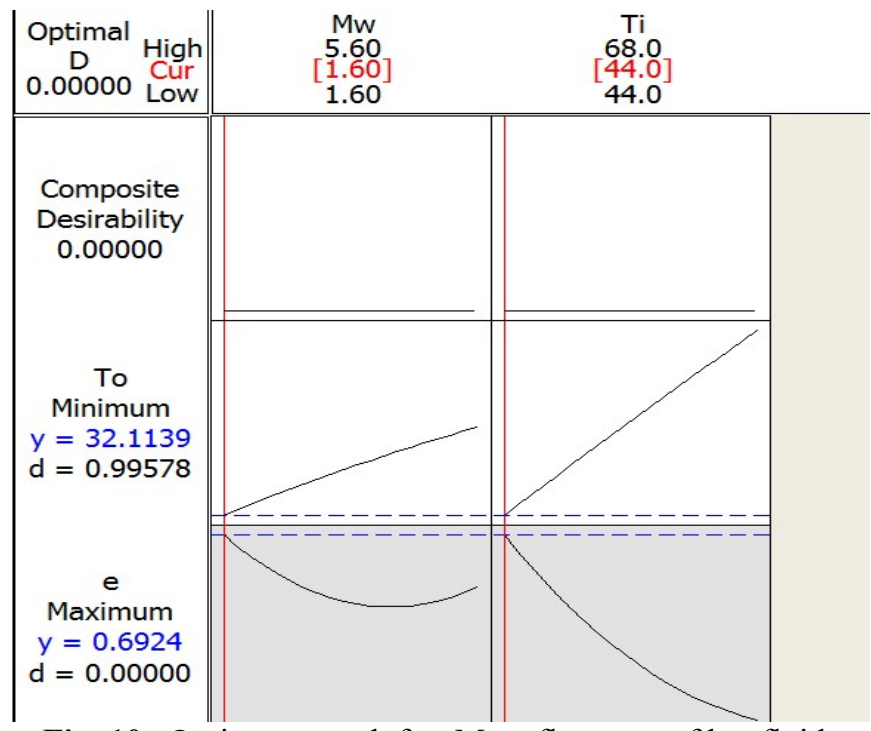

Fig. 10. Optimum graph for Mass flow rate of hot fluid ( $60 \%$ of water) v/s Inlet temperature (Ti) Taguchi Techniqe

Fig.9 Fig.10 the optimum effectiveness for the compact heat exchanger is clearly obtained at mass flow rate of 1.6 LPM and inlet temperature $44^{\circ} \mathrm{C}$, which has been represented graphically

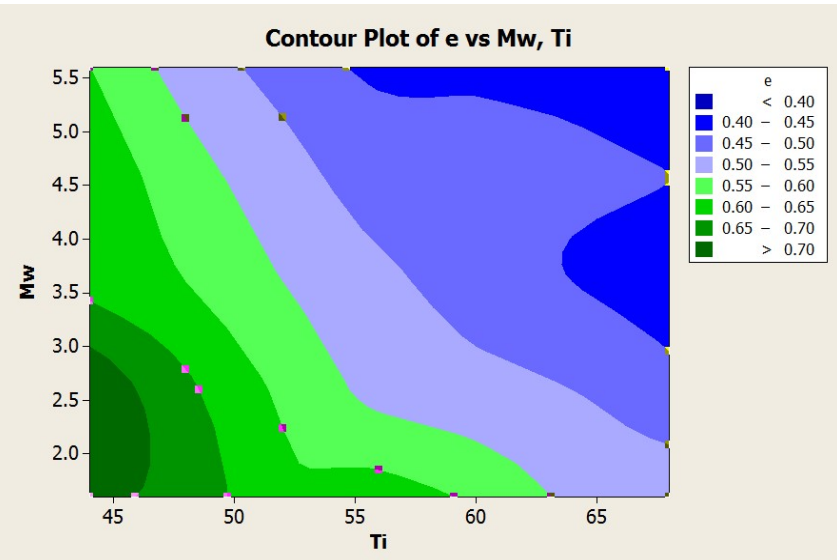

Fig. 11. Contour plot for effectiveness(e), Mass flow rate (water) and inlet temperature for hot fluid by Taguchi Technique

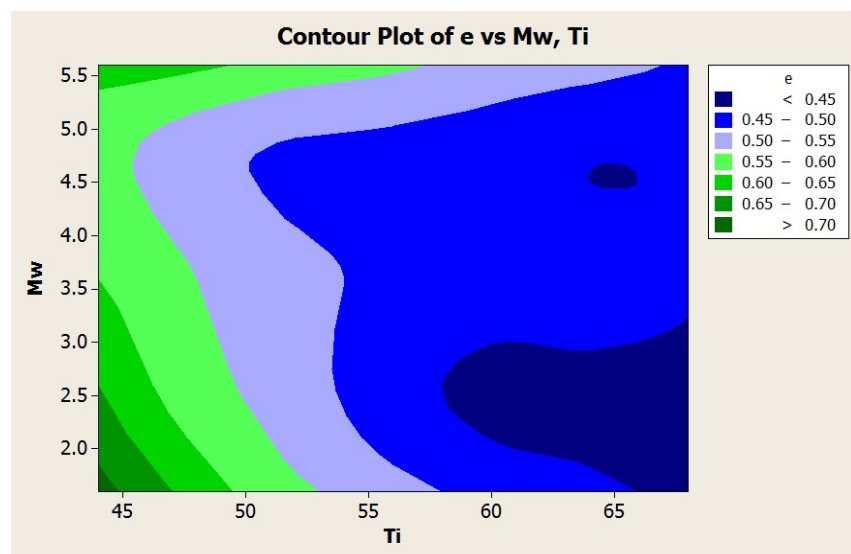

Fig. 12. Contour plot for effectiveness(e), Mass flow rate ( $60 \%$ of water) and inlet temperature for hot fluid by Taguchi Technique
Fig.11 Fig.12 shows contour plot for mass flow rate, inlet temperature and effectiveness where the values for mass flow rate and inlet temperature varies with ranges in effectiveness can be observed.

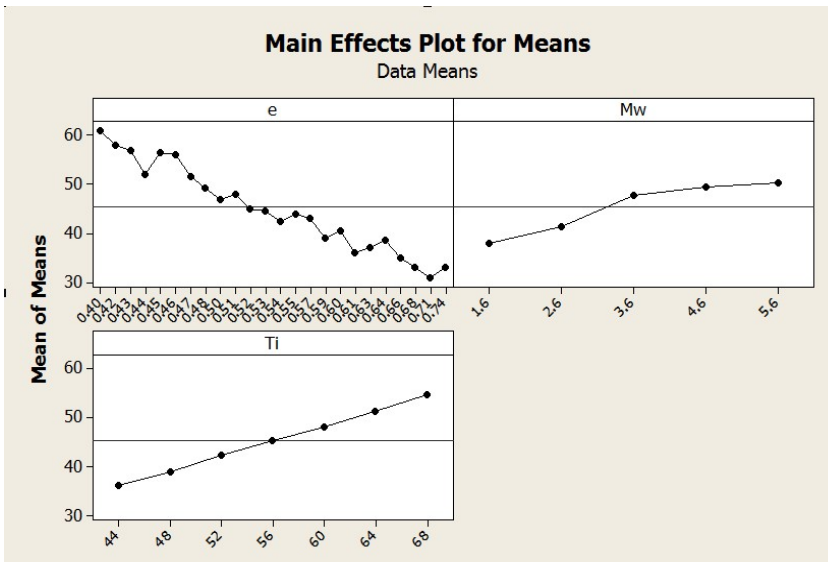

Fig. 13. Mean graphical dāa for effectiveness (e), mass flow rate(water) and inlet temperature (Ti) using Taguchi method

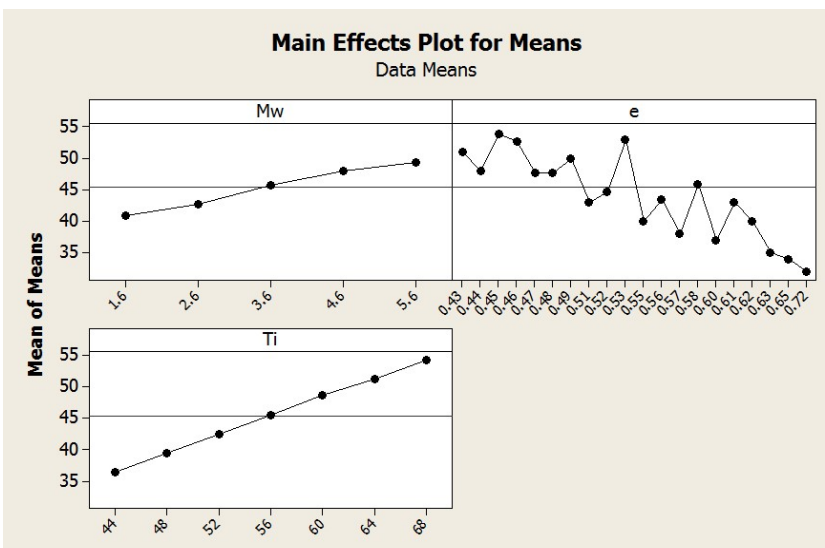

Fig. 14. Mean graphical data for effectiveness (e), mass flow rate $(60 \%$ of water) and inlet temperature (Ti) using Taguchi method

Fig.13 Fig.14 shows the mean value representation using Taguchi method for effectiveness, mass flow rate and inlet temperature where it has been observed that for increase in mass flow rate, inlet temperature, and effectiveness keeps on decreasing.

\section{VALIDATION:}

From table-1, and table-2 statistical result and observation it can be concluded that for a compact heat exchanger for different mixtures of coolant with different mass flow rates and also with varying temperature the best and optimum effectiveness for the given surface area can be obtained. A slight error of $10-15 \%$ is can be seen for both experimental as well as analytical. This could be the best effectiveness for the given compact heat exchanger experimentally as well as analytical procedure followed so far. 
As we can observed consistent result of effectiveness is reflected when the flow rate was 1.6 LPM and for different temperature.

When the experiment was conducted for different ratios of Glycol-Water mixture we observed the effectiveness continuously dropped with increases of glycol percentage in the mixture from this we can infer that pure water being a coolant is more effective than the mixture

One of the possibilities for reduction in effectiveness with the increase in glycol percentage in the mixture is combined specific heat value by magnitude with the specific heat of pure water

\section{CONCLUSION:}

From the experimental investigations it is observed that,

1. When mass flow rate of hot fluid (liquid) is increased effectiveness decreases with constant flow rate of cold fluid (air)

2. At constant mass flow rates of hot and cold fluids, when inlet temp of hot fluid is increased, effectiveness decreases and heat transfer rate increases.

3. At lower temp and constant mass flow rate of hot fluid, the effectiveness is highest at lower mass flow rate of hot fluid (1.6LPM)

4. Experiments were conducted with pure water and mixture of water and coolant (with $60 \%, 50 \%$, and $40 \%$ of water) and it is observed that the pure water gives higher effectiveness compared to coolant and its mixture. When $\%$ of water is reduced in the mixture then effectiveness reduces.

5. From experimental values we observe that NTU increases with decreasing inlet temp of hot fluid keeping mass flow rate of hot and cold fluids constant

6. With increased mass flow rate of hot fluid when mass flow rate of cold fluid is kept constant it is observed that NTU decreases

7. It is observed that NTU increases in all the tested conditions and hence effectiveness increases.

8. At constant mass flow rate of hot and cold fluid, with increasing the temp of hot fluid, temp drop increases but effectiveness decreases. Also rate of heat transfer rate is increases.

9. A statistical and analytical comparison between various parameters is obtained from the Minitab software.

10. The results and discussion for experimental, Cprogramming and Statistical analysis exhibit a near 4 $6 \%$ error which is almost acceptable.

\section{ACKNOWLEDGMENT}

I would like to express my special thank of gratitude to my Guide as well as Principal, H.O.D and teaching and non teaching staff of mechanical engineering department and management of S V C E Bengaluru for providing their valuable guidance and overwhelming support to carrying out this work.

\section{REFERENCES}

[1]. "A Critical Review on Different Heat Exchangers Used For Heat Transfer between Two Fluids" by Avinash D. Jadhav, Tushar A. Koli, Vijay H. Patil Department of Mechanical Engineering GF's Godavari College of Engineering, Jalgaon, INDIA International Journal of Engineering, Business and Enterprise Applications (IJEBEA)

[2]. "Study on Performance Evaluation of Automotive Radiator" by JP Yadav, Associate Professor, Chandra Shekhar Azad University of Agriculture \& Technology, Campus-Etawah (U.P.), Bharat Raj Singh, Professor and Associate Director, SMS Institute of Technology, Kashimpur, Lucknow S-JPSET: ISSN: 2229-7111, Vol. 2, Issue 2

[3]. "Automotive Radiator Performance - Review" by Pawan S. Amrutkar, Sangram R. Patil, International Journal of Engineering and Advanced Technology (IJEAT) ISSN: 2249 - 8958, Volume-2, Issue-3, February 2013

[4]. "Effect of Variation in Pitch of Tube on Heat Transfer Rate in Automobile Radiator by CED Analysis" by P. K. Trivedi, N. B.Vasava, International Journal of Engineering and Advanced Technology (IJEAT) ISSN: 2249 - 8958, Volume-1, Issue-6, August 2012.

[5]. "Cooling Systems in Automobiles \&Car" by Gogineni. Prudhvi, Gada.Vinay, G.Suresh Babu International Journal of Engineering and Advanced Technology (IJEAT) ISSN: 2249 - 8958, Volume-2, Issue-4, April 2013.

[6]. "Thermal Analysis of Shell and Tube Heat Ex-Changer Using C and Ansys" by Av.Hari Haran, Bg.Ravindra Reddy and $\mathrm{Cb}$.Sreehari, International Journal of Computer Trends and Technology (IJCTT) - volume 4 Issue 7-July 2013.

[7]. "Effect of Nano fluids And Mass Flow Rate Of Air On Heat Transfer Rate In Automobile Radiator By CFD Analysis" by J.R. Patel, A.M. Mavani, IJRET: International Journal of Research in Engineering and Technology eISSN: 2319-1163 | pISSN: 2321-7308.

[8]. "Thermal performance analysis of cross-flow unmixedunmixed heat exchanger by the variation of inlet condition of hot fluid" by Dr. M K Chopra, Ramjee Singh Prajapati, International Refereed Journal of Engineering and Science (IRJES), ISSN (Online) 2319183X, (Print) 2319-1821, Volume 3, Issue 1 (January 2014), PP. 29-31

[9]. "Compact heat exchangers" by W.M.Kays and London, IInd edition book. 